\title{
PEMANFAATAN MEDIA PEMBELAJARAN BERBASIS SMARTPHONE PADA MATERI PENCEMARAN LINGKUNGAN UNTUK MENINGKATKAN HASIL BELAJAR SISWA
}

\author{
${ }^{1}$ Linda Sari, ${ }^{2}$ Haning Hasbiyati \\ ${ }_{123}$ Pendidikan Biologi, Universitas Islam Jember \\ 1 lindasariputri97@gmail.com,2haninghasbiyati@gmail.com
}

\begin{abstract}
ABSTRAK
Saat ini kemajuan teknologi sangatlah pesat, termasuk kemajuan penggunaan smartphone. Berdasarkan hasil observasi pada mata pelajaran IPA nilai siswa masih banyak yang dibawah KKM terutama pada saat ulangan akhir. Oleh karena itu peneliti memanfaatkan smartphone sebagai media dalam menunjang proses pembelajaran. Penelitian ini menggunakan PTK, pengumpulan datanya menggunakan kuantitatif tes hasil belajar kognitif. Subyek penelitian ini sebanyak 18 siswa. Berdasarkan hasil penelitian tersebut rata- rata nilai kognitif siswa pada siklus I sebesar 75\%. Pada siklus II diperoleh rata-rata nilai kognitif siswa sejumlah $81 \%$, maka terjadi peningkatan sejumlah $6 \%$. Maka penerapan media berbasis smartphone sangat tepat untuk membantu keberhasilan proses pembelajaran.
\end{abstract}

Kata kunci: Media pembelajaran berbasis smartphone, Hasil Belajar

\section{ABSTRACT}

Technology advances are currently very rapid, including the progress of smartphone usage. Based on the results of obervation on science subjects there are still many student under thr KKM especially at the end of the day. Therefore researchers use smartphones as a medium to support the learning process. This research uses CAR, thedata collection use quantitative tests of cognitive learning outcomes. The subjects of this study were 18 students. Based on these results the average cognitive value of students in cycle I is $75 \%$. In cycle II the average cognitive value of students is $81 \%$. The an increase of $6 \%$. Then the application of smartphone based media $i$ very appropriate to help the success of the learning process.

Key words: smartphone based learnig media, learning outcomes

\section{PENDAHULUAN}

\section{Latar Belakang}

Pendidikan merupakan aspek yang sangat penting dalam pembangunan bangsa karena dari aspek pendidikan inilah karakter suatu bangsa dibentuk dan dikembangkan. Pembaharuan dalam berbagai pendidikan senantiasa dilakukan untuk mewujudkan tercapainya tujuan pendidikan nasional. Pendidikan merupakan salah satu bidang yang tidak lepas dari perkembangan teknologi. Saat ini kemajuan teknologi sangatlah pesat, termasuk didalamnya adalah kemajuan dalam penggunaan smartphone.

Berdasarkan hasil Obsevasi yang telah di lakukan di MTs. Al-Ishlah Mayang melalui wawancara dengan Guru Mata Pelajaran IPA diperoleh informasi bahwa nilai siswa masih banyak yang dibawah KKM terutama pada saat ulangan akhir semester nilai siswa banyak yang turun tidak mencapai KKM dari pada saat tugas hariannya, dengan KKM yang ditentukan sekolah adalah 70 . Untuk itu agar siswa tertarik dan termotivasi untuk belajar 
peneliti memanfaatkan Media pembelajaran berbasis smartphone untuk meningkatkan hasil belajar siswa.

\section{Rumusan Masalah}

Apakah media pembelajaran berbasis Smartphone dapat meningkatkan hasil belajar siswa pada materi pencemaran lingkungan kelas VII MTs Al- Ishlah Mayang

\section{Tujuan Penelitian}

Untuk mengetahui peningkatan hasil belajar siswa melalui penerapan media pembelajaran berbasis Smartphone pada materi pencemaran lingkungan di kelas VII MTs Al- Ishlah Mayang.

\section{METODE PENELITIAN}

Penelitian ini dilakukan di kelas VII MTs Al Ishlah Mayng tahun ajaran 2018/2019 dengan jumlah siswa 18 orang. Penelitian ini dirancang menjadi 2 siklus yang pada setiap siklusnya meliputi perencanaan, pelaksanaan, observasi, evaluasi atau refleksi. Apabila sudah diketahui letak keberhasilan dan hambatan dari pelaksanaan atau penelitian yang baru diselesaikan dalam siklus pertama, maka peneliti menentukan rancangan untuk proses penelitian di siklus kedua. Fungsi dari penenlitian dari siklus kedua yaitu untuk lebih meyakinkan dan mengembangkan penelitian pada siklus pertama. Proses pelaksanaan tindakan kedua sama dengan pelaksaan di siklus pertama. Metode pengumpulan data diperoleh dari tes objektif. Tes objektif digunakan untuk mengetahui hasil belajar siswa selama proses pembelajaran IPA menggunakan media berbasis smartphone.

\section{HASIL DAN PEMBAHASAN}

\section{a. Hasil Belajar}

Hasil belajar merupakan kemampuan yang diperoleh individu setelah proses belajar berlangsung, yang dapat memberikan perubahan tingkah laku baik pengetahuan, pemahaman, sikap dan ketrampilan siswa sehingga menjadi lebih baik dari sebelumnya. Peningkatan hasil belajar siswa menggunakan media berbasis smartphone dapat dilihat dengan mengukur peningkatan tes hasil belajar siklus I dan siklus II. Data hasil belajar diperoleh peneliti dari hasil evaluasi berupa ulangan harian siswa dari tiap siklus setelah dilaksanakanya tindakan pada tiap siklus. Perbandingan hasil belajar siswa melalui pembelajaran menggunakan media pembelajaran berbasis smartphone pada siklus I dan siklus II pada materi pencemaran lingkungan disajikan pada Gambar 1.

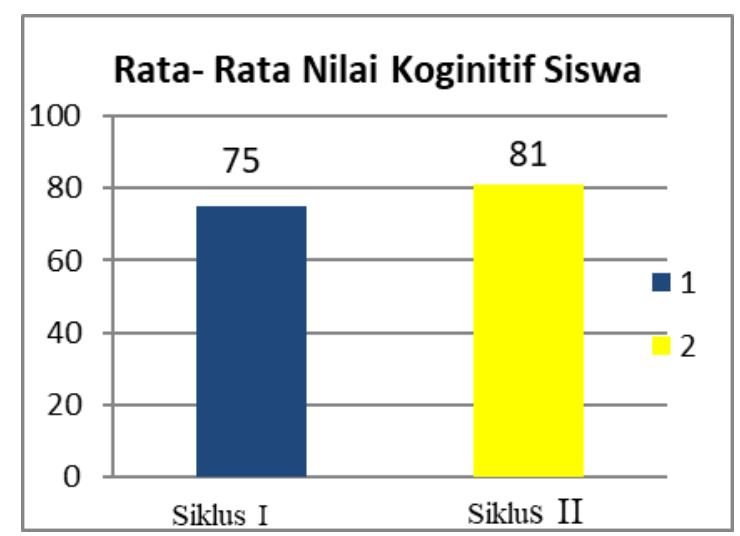

Gambar .1 Perbandingan Hasil Belajar Siswa

Berdasarkan data yang diperoleh dari hasil penelitian tersebut rata- rata nilai kognitif siswa pada siklus I sebesar $75 \%$. Pada siklus II diperoleh rata-rata nilai 
kognitif siswa sejumlah $81 \%$. Dari hasil tersebut terdapat peningkatan sejumlah $6 \%$ dan data ini sudah mencapai pada indikator keberhasilan yakni apabila adanya peningkatan hasil belajar siswa dalam setiap pembelajaran dari siklus I sampai siklus II.

Maka penerapan media berbasis smartphone sangat tepat untuk membantu keberhasilan proses pembelajaran. Hal ini sesuai dengan hasil peningkatan antara siklus I dengan siklus II sebesar 6\%. Setelah diperoleh data- data dari siklus I dan siklus II, berdasarkan grafik diatas terlihat terjadi peningkatan hasil belajar sebelum dan sesudah perlakuan penerapan media berbasis smartphone pada materi pencemaran lingkungan. Hal ini sesuai dengan (Hasbiyati, 2017) diperoleh hasil belajar siswa dengan menggunakan test kognitif yang diperoleh berupa gain score dengan kriteria keberhasilan tinggi sebesar 0,703 .

\section{KESIMPULAN}

Pembelajaran melalui media berbasis smartphone dapat meningkatkan hasil belajar siswa pada materi pencemaran lingkungan, hal ini dapat di buktikan dengan hasil tes ketuntasan klasikal pada siklus I mencapai angka $77,78 \%$ dan pada siklus II mencapai angka 100\%. Oleh karena itu dari siklus I ke siklus II mengalami peningkatan sebesar $33 \%$.

\section{DAFTAR PUSTAKA}

Aimah, M., Hasbiyati, H., \& Khusnah, L. (2018). Penggunaan Aplikasi Macromedia
Flash 8 Sebagai Media Pembelajaran Interaktif Untuk Meningkatkan Hasil Belajar Siswa. Jurnal Bioshell, 6(1). http://ejurnal.uij.ac.id/index.php/BIO/ar ticle/view / 227

Arikunto. 2010. Prosedur Penelitian: Suatu Pendekatan Praktek. Jakarta: PT. Rineka Cipta.

Hasbiyati, Haning. 2017. E-Book Berekstensi Epub Sebagai Media Pembelajaran Berbasis Smartphone. Jember: UIJKyai Mojo

Hasbiyati, H., \& Khusnah, L. (2016). Pengembangan E-Book Berekstensi Epub Pada Pembelajaran IPA SMP. Jurnal Bioshell, 5(1).

http:/ / ejurnal.uij.ac.id/index.php/BIO/ar ticle/view/49

Purwanto. 2008. "Metodologi Penelitian Kuantitatif". Yogyakarta: Pustaka Pelajar

Sugiyono. 2017. Metode Penelitian Kuantitatif, Kualitatif dan Kombinasi (Mixed Methods). Bandung. Alfabeta

Widodo, Wahono. 2017. Ilmu Pengetahuan Alam. Jakarta. Pusat Kurikulum dan Perbukuan, Balitbang Kemendikbud. 